\title{
Initial screening of vegetable amaranth landraces toward extending the vegetable list
}

\author{
Saubhik Das* \\ Department of Botany, Taki Government College, Taki, North 24 Parganas, West Bengal, India
}

Received: 14.05.2017

Accepted: 10.06 .2017

Published: 15.06.2017

*Address for correspondence:

Saubhik Das, Department of Botany, Taki Government

College, Taki, North 24

Parganas, West Bengal, India.

E-mail: sbhk_das@yahoo. com

\begin{abstract}
Vegetable amaranth is considered as one of the most favorite vegetables in the world, especially in the hot and humid tropical regions of the globe. Two of them are most popular, i.e., Amaranthus tricolor and Amaranthus blitum, both are represented by a large number of morphotypes or landraces or varieties, which are taxonomically ill-defined, many of them are consumed as palatable vegetables as they look like the conventional cultivars. Due to wide morphological diversity and presence of many synonyms both species are supposed to represent two species complex or aggregates, namely, "Tricolor complex" and "Blitum complex". Two new species have been identified from their landraces. In the present investigation, morphometric analysis along with biochemical and molecular methodologies were applied to explore the relative closeness among few well known, popular vegetables, and few less known landraces for better utilization of the crop biodiversity of vegetable amaranths. The experimental data were statistically analyzed and separate dendrograms were computed on three parameters (morphology, isozyme polymorphism, and inter simple sequence repeat band profile). The members of "Tricolor complex" were clustered together in a single group along with two newly introduced species Amaranthus bengalense (a member of "Blitum complex") and Amaranthus parganensis (a gynomonoecious member of "Tricolor complex"). The "Tricolor complex" represents a plexus of species with varying sexual behavior from gynomonoecy to monoecy and indicates probable origin of monoecious $A$. tricolor varieties or landraces from gynomonecious member such as $A$. parganensis as recent introduction. The study indicated a close alliance between $A$. bengalense, A. parganensis, A. tricolor landrace, and popular $A$. tricolor varieties which consolidated the feasibility of utilizing the landrace and newly introduced species as potential vegetable.
\end{abstract}

KEY WORDS: Crop biodiversity, interrelationship, landraces, new potential vegetable, species complex, vegetable amaranths

\section{INTRODUCTION}

Vegetables are the essential parts of any diet as a source of protein, vitamins, minerals, and dietary fibers. Vegetable amaranths are probably the most widely consumed and popular vegetable in the hot humid tropical regions of Asia and Africa (Schnetzler and Breene, 1994) due to its mild spinach such as flavor and high nutritive value. It is also ranked as one of the top five vegetable in antioxidant properties, in having bioactive components (Willett, 2001). Tumor cell proliferation and cyclooxygenase inhibitory compounds have been isolated from certain vegetable amaranths (Amaranthus tricolor) (Jayaprakasam et al., 2004).

High yield, ability to grow on virtually any type of soil even in marginal areas not needing any special agricultural inputs, adaptability to hot humid tropical climate are the prime reasons for its popularity among the farmers. Leaves and tender juicy stem of several amaranth species are edible in different parts of the world with varying acceptability but two of them (A. tricolor and Amaranthus blitum) are very popular. Both are represented by a large number of varieties, morphotypes, or landraces. A large number of synonyms and misapplication of names have created ambiguity in infraspecific delimitation. As such several authors (Das, 2013; Mosyakin and Robertson, 1996; Das and Iamonico, 2014) suggested to consider both species as two separate species complex or aggregates, i.e. "Tricolor complex" and "Blitum complex". Two new species - Amaranthus bengalense, a monoecious member (Das and Iamonico, 2014) and Amaranthus parganensis, a gynomonoecious member (Das, 2015) have been described from the Lower Gangetic plain of West Bengal 
from the crop-wild relatives or landraces, which are equally palatable like conventional cultivars.

In the present investigation, along with few well-known vegetable amaranths few less known locally consumed members included in both "Tricolor complex" and "Blitum complex" have been studied to explore the relative closeness among the vegetable amaranths, to widen the vegetable list also to have an idea about phylogeny of vegetable amaranths.

\section{MATERIALS AND METHODS}

\section{Materials}

Few common popular vegetable amaranths (A. tricolor var. tricolor L., A. tricolor var. tristis (L.) Thellung, A. tricolor var. acutus S. Das, and $A$. bengalense Saubhik Das and Iamonico), few less known vegetables (A. parganensis Saubhik Das, A. blitum var. oleraceus, and one landrace of A. tricolor var. tricolor), and one weed member Amaranthus viridis (occasionally used as vegetable elsewhere) were incorporated in the present investigation.

\section{Morphological Study}

27 notable morphological characters (both qualitative and quantitative) with variable character states were considered in morphometric analysis. Morphological features taken into consideration were - leaf shape, inflorescence pattern, position of male and female flowers; comparative length of bracts, bracteoles, and tepals; number of tepal lobes and stamens; tepal shape and apices; fruit and seed character, etc.

\section{Isozyme Polymorphism Study}

Enzyme extraction was carried out according to the method of Wetter and Dyck (1983). Seedling samples of $100 \mathrm{mg}$ each were extracted with $1 \mathrm{ml}$ of $0.2 \mathrm{MTris}-\mathrm{HCl}$ buffer $\mathrm{pH}-8.5$ containing $0.056 \mathrm{M}$ 2-mercaptoethanol and $1 \mathrm{M}$ sucrose. Isozyme variability was analyzed by native polyacrylamide gel electrophoresis following Studier (1973). Gel was stained for acid phosphatase (ACP) activity following the method of Brewbaker et al. (1968).

\section{Inter Simple Sequence Repeat (ISSR) Polymorphism Study}

The genomic DNA from different seedling samples was isolated following cetyltrimethylammonium bromide (CTAB) method with slight modification. Three ISSR oligonucleotide primers, $(\mathrm{GACA})_{4},(\mathrm{CAA})_{5}$, and $(\mathrm{GA})_{8}$ were applied for polymorphism analysis. Polymerase chain reactions were performed in $25 \mu \mathrm{l}$ of reaction mixture containing $20 \mathrm{mg}$ of genomic DNA, 1 unit of Taq DNA polymerase, $10 \mathrm{mM}$ of Tris - $\mathrm{HCl}$ (pH 8.0) buffer, $2 \mathrm{mM}$ of $\mathrm{MgCl}_{2}, 0.25 \mu \mathrm{M}$ of each deoxynucleotide, and $0.2 \mu \mathrm{M}$ oligonucleotide primers. Amplifications were carried out in a thermocyclar programmed with initial denaturing for $5 \mathrm{~min}$ at $94^{\circ} \mathrm{C}$ followed by 40 cycles of $45 \mathrm{~s}$ at $94^{\circ} \mathrm{C}, 1 \mathrm{~min}$ at annealing temperature (primer specific), and $2 \mathrm{~min}$ at $72^{\circ} \mathrm{C}$ for extension with final extension for $7 \mathrm{~min}$ at $72^{\circ} \mathrm{C}$. The products from amplifications were separated in $2 \%$ agar gel using 100 bp ladders.

\section{Statistical Analysis}

In case of morphological analysis, on the basis of presence or absence of a particular character state in all the samples, a similarity matrix was prepared giving each character state a definite number. Percentage-based pairing affinity (PA) values between different combinations of species pairs were calculated by the following formula:

$$
\begin{aligned}
& \text { Character state common } \\
& \mathrm{PA}=\frac{\text { to sample } \mathrm{A} \text { and } \mathrm{B}}{\text { Total number of character states }} \times 100 \\
& \text { in sample A and B }
\end{aligned}
$$

In both the cases of isozyme and ISSR polymorphism analysis, pairing affinity values for different combinations of sample pairs were calculated from the band profiles by the following formula:

$$
\mathrm{PA}=\frac{\begin{array}{l}
\text { Number of isozyme or ISSR bands } \\
\text { common to sample A and B }
\end{array}}{\begin{array}{l}
\text { Total number isozyme or ISSR } \\
\text { bands in sample A and B }
\end{array}} \times 100
$$

From the PA values of each parameter, three separate dendrograms were computed using statistica 13.2 cluster analysis software from Dell.

\section{RESULTS AND DISCUSSION}

\section{Morphological Study}

Morphological studies applying 27 prominent morphological characters revealed an appreciable similarity between common cultivars and local landraces of monoecious $A$. tricolor. Surprisingly gynomoecious $A$. parganensis showed striking similarity with $A$. tricolor. Although A. bengalense distinctly differs from A. tricolor in having comparatively smaller plant body, trailing habit, 
small terminal inflorescence, and indehiscent capsule it showed very close relationship with $A$. tricolor. Pairing affinity values showed wide range of variability that ranged from 40.74\% (A. tricolor var. tricolor and A. blitum var. oleraceus) to $96.29 \%$ (A.parganensis and A. tricolor landrace) (Table 1). Pairing affinity values between different $A$. tricolor varieties and landraces varied from $55.55 \%(A$. tricolor var. tricolor and $A$. tricolor var. acutus) to $88.88 \%$ (A. tricolor var. tristis and A. tricolor landrace).

Dendrogram (Figure 1) computed from pairing affinity values showed clear clustering of $A$. tricolor varieties and landraces with their close allies $A$. bengalense and A. parganensis in a single large cluster (Group A) though A. tricolor var. acutus showed wide divergence from other A. tricolor varieties and a close association with $A$. viridis and A. blitum var. oleraceus in Group B.

\section{Isozyme Polymorphism Study of ACP}

The compiled zymogram (Figure 2) showed 18 polymorphic bands distributed in different taxa. A. tricolor var. tricolor landrace showed the highest polymorphism while $A$. tricolor var. tristis showed the least. Pair-wise monomorphism percentage or pairing affinity values ranged from $33.33 \%$ (A. parganensis and A. blitum var. oleraceus) to $95.23 \%$ (A.parganensis and A.tricolor landrace) (Table 2). Dendrogram

Table 1: Pairing affinity values on morphometric analysis

\begin{tabular}{ccccccccc}
\hline & A & B & C & D & E & F & G & H \\
\hline A & 100 & & & & & & & \\
B & 85.18 & 100 & & & & & & \\
C & 81.48 & 81.48 & 100 & & & & & \\
D & 85.18 & 85.18 & 88.88 & 100 & & & & \\
E & 81.48 & 81.48 & 85.18 & 96.29 & 100 & & & \\
F & 55.55 & 55.55 & 55.55 & 62.96 & 59.25 & 100 & & \\
G & 66.66 & 66.66 & 62.96 & 66.66 & 62.96 & 62.96 & 100 & \\
H & 44.44 & 40.74 & 59.25 & 51.85 & 55.55 & 44.44 & 48.14 & 100 \\
\hline
\end{tabular}

A: Amaranthus bengalense, B: Amaranthus tricolor var. tricolor, C: A. tricolor var. tristis, D: Amaranthus parganensis, E: Amaranthus tricolor var. tricolor landrace, F: Amaranthus tricolor var. acutus, $\mathrm{G}$ : Amaranthus viridis, $\mathrm{H}$ : Amaranthus blitum var. oleraceus

Table 2: Pairing affinity values on acid phosphatase polymorphism

\begin{tabular}{ccccccccc}
\hline & A & B & C & D & E & F & G & H \\
\hline A & 100 & & & & & & & \\
B & 94.11 & 100 & & & & & & \\
C & 93.33 & 87.50 & 100 & & & & & \\
D & 77.77 & 84.21 & 70.58 & 100 & & & & \\
E & 84.21 & 90.00 & 77.77 & 95.23 & 100 & & & \\
F & 75.00 & 82.35 & 66.66 & 66.66 & 73.68 & 100 & & \\
G & 62.50 & 58.82 & 66.66 & 44.44 & 52.63 & 62.50 & 100 & \\
H & 50.00 & 47.05 & 53.33 & 33.33 & 42.10 & 50.00 & 50.00 & 100 \\
\hline
\end{tabular}

A: Amaranthus bengalense, B: Amaranthus tricolor var. tricolor, C: A. tricolor var. tristis, D: Amaranthus parganensis, E: Amaranthus tricolor var. tricolor landrace, F: Amaranthus tricolor var. acutus, $\mathrm{G}$ : Amaranthus viridis, $\mathrm{H}$ : Amaranthus blitum var. oleraceus
(Figure 3) computed from pairing affinity values showed two large distinct clusters or groups. Group - A comprised all the members of "Tricolor complex" along with two newly introduced species. Group B comprised A. blitum var. oleraceus and weed $A$. viridis.

\section{ISSR Polymorphism Study}

ISSR polymorphism analysis with three different ISSR primers showed varied degree of amplification. The best amplification was achieved with the primer (GACA) developing 24 polymorphic bands distributed in different

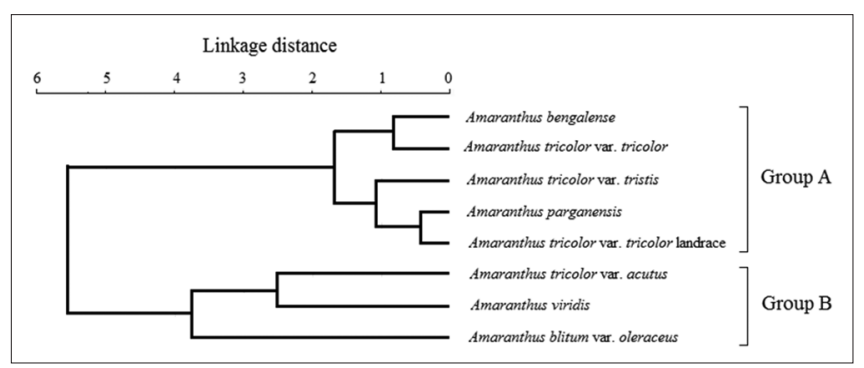

Figure 1: Dendrogram computed from morphological features showing grouping of taxa

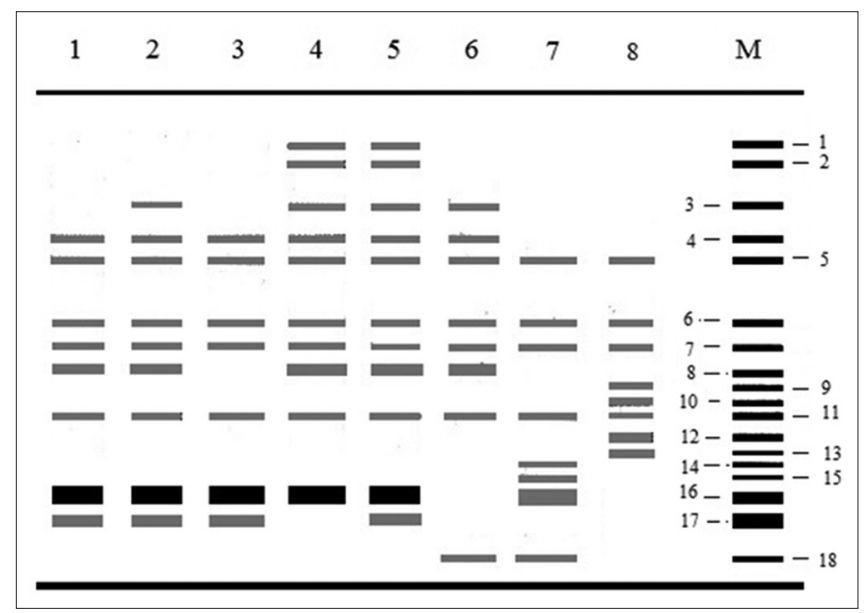

Figure 2: Zymogram of acid phosphatase isozymes (diagrammatic). (1) Amaranthus bengalense, (2) Amaranthus tricolor var. tricolor, (3) Amaranthus tricolor var. tristis, (4) Amaranthus parganensis, (5) Amaranthus tricolorvar. tricolor landrace, (6) A. tricolorvar. acutus (7) Amaranthus viridis, and (8) Amaranthus blitum var. oleraceus, (M) compiled zymogram

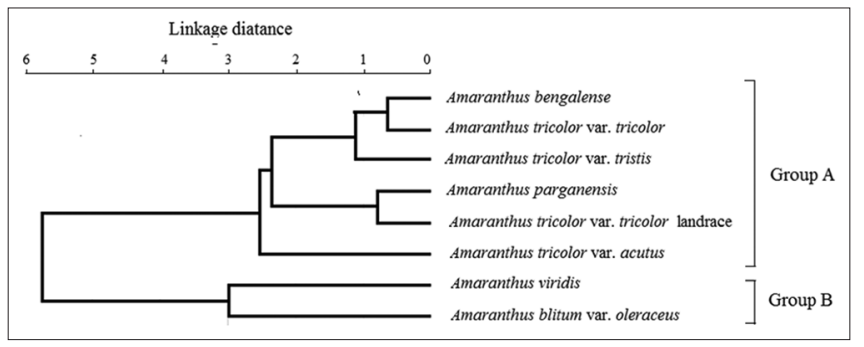

Figure 3: Dendrogram computed from isozyme polymorphism of acid phosphatase 
taxa (Figure 4). Pairing affinity values or percentage-based monomorphism ranged from 16.66\% (A. parganensis and A. tricolor var. acutus) to $71.42 \%$ (A. tricolor var. tricolor and $A$. tricolor var. tristis; $A$. tricolor var. tristis and $A$. tricolor landrace) (Table 3). Grouping patterns in the dendrogram (Figure 5) computed from pairing affinity values showed exact concomitance with that of morphological dendrogram.

Table 3: Pairing affinity values on ISSR polymorphism analysis

\begin{tabular}{ccccccccc}
\hline & A & B & C & D & E & F & G & H \\
\hline A & 100 & & & & & & & \\
B & 60.00 & 100 & & & & & & \\
C & 44.44 & 71.42 & 100 & & & & & \\
D & 40.00 & 54.54 & 66.66 & 100 & & & & \\
E & 60.00 & 62.50 & 71.42 & 54.54 & 100 & & & \\
F & 47.61 & 58.82 & 53.33 & 16.66 & 58.82 & 100 & & \\
G & 36.36 & 55.55 & 50.00 & 30.76 & 66.66 & 52.63 & 100 & \\
H & 41.66 & 60.00 & 44.44 & 40.00 & 50.00 & 38.09 & 54.54 & 100 \\
\hline
\end{tabular}

ISSR: Inter simple sequence repeat, A: Amaranthus bengalense, B: Amaranthus tricolor var. tricolor, C: A. tricolor var. tristis, $\mathrm{D}$ : Amaranthus parganensis, E: Amaranthus tricolor var. tricolor landrace, F: Amaranthus tricolor var. acutus, G: Amaranthus viridis, $\mathrm{H}$ : Amaranthus blitum var. oleraceus

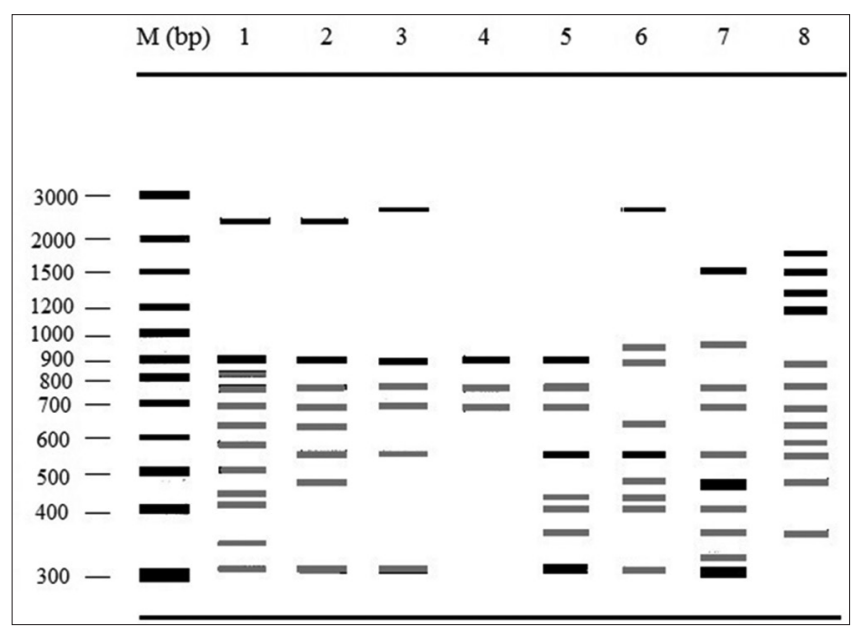

Figure 4: Inter simple sequence repeat fragment polymorphism in different taxa (diagrammatic). (M) DNA marker, (1) Amaranthus bengalense, (2) Amaranthus tricolor var. tricolor, (3) A. tricolor var. tristis, (4) Amaranthus parganensis, (5) A. tricolorvar. tricolor landrace, (6) A. tricolor var. acutus, (7) Amaranthus viridis, and (8) Amaranthus blitum var. oleraceus

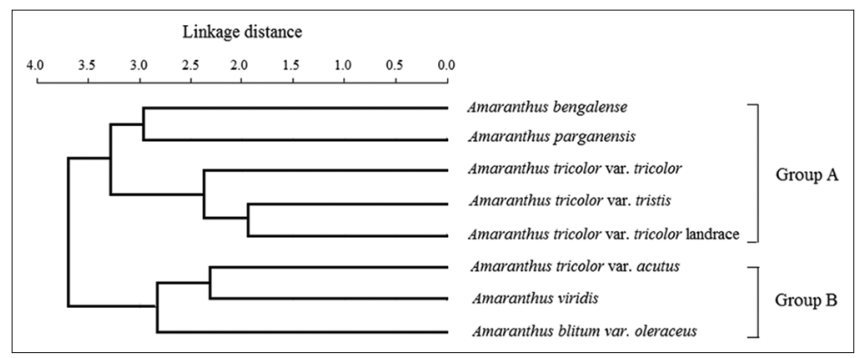

Figure 5: Dendrogram computed from inter simple sequence repeat fragment analysis
Species delimitation in vegetable amaranths is quite ambiguous due to its wide morphological variability. Few species of vegetable amaranths are edible of which two most common and popular species are $A$. tricolor and A. blitum. A.tricolor is a moderate to robust herb with flowers arranged in small axillary glomerulus and terminal compound inflorescence of agglomerated cymes, circumscissile capsule, and blackish-brown seeds. A. blitum is comparatively smaller, erect to prostrate herb with flowers arranged in small terminal spike, and small axillary glomerulus. Fruits are compressed subglobose indehiscent capsule with small black seeds, 1.1-1.2 mm in diameter. Infraspecific variability of $A$. tricolor is addressed by introducing taxa at the variety level; at least three varieties are recognized, namely, A. tricolor var. tricolor, A. tricolor var. tristis, and A. tricolor var. acutus. Due to presence of a large number of morphotypes or landraces and available synonyms both $A$. tricolor and A. blitum are supposed to represent two species complex or aggregates, i.e., "Tricolor Complex" and "Blitum Complex". A robust gynomonoecious species $A$. parganensis was identified from A. tricolor landraces from Lower Gangetic plain of West Bengal. Another species $A$. bengalense was identified from A. blitum landraces. In Lower Gangetic plain of West Bengal, "Tricolor Complex" is represented by varieties and landraces of $A$. tricolor and $A$. parganensis and "Blitum complex" is represented by $A$. blitum var. oleraceus, A. blitum var. blitum and $A$. bengalense.

Vegetable amaranths are mostly included in Amaranthus subgen Albersia. Members of "Tricolor complex" are included in Albersia section Pentamorion and members of "Blitum complex" along with $A$. viridis are included in Albersia section Blitopsis. Both the subsects are generally delimited on the basis of dehiscence and indehiscence of fruit.

Morphological evidences have played a significant role in solving taxonomic disputes in amaranths (Costea and DeMason, 2001; Costea and Tardif, 2003b; Das, 2012b). Beside Morphological parameters, biochemical and molecular parameters such as - Isozymes (Chan and Sun, 1997; Hauptli and Jain, 1984; Iduna et al., 2005), Random Amplified Polymorphic DNA (Transue et al., 1994), ISSR, Amplified Fragment Length Polymorphism and ITS (Costea et al., 2006; Nolan et al., 2010; Stefunova et al., 2014; Xu and Sun, 2001) were employed successfully to address the queries regarding taxonomic delimitation and phylogeny in amaranths. In the present investigation besides morphology, isozyme polymorphism of ACP, ISSR fragment polymorphism were employed to trace the relative closeness among the common cultivars of 
vegetable amaranths with their landraces or crop wild relatives.

Separate dendrograms on different parameters showed significant concomitance in grouping of taxa with minor variations at the similarity levels or linkage distance. All the taxa of "Tricolor complex" including two newly introduced species and landrace were included in a single cluster except $A$. tricolor var. acutus that showed close affinity with $A$. viridis and $A$. blitum var. oleraceus (a member of "Blitum complex"). A. bengalense though is a member of "Blitum complex" always showed close alliance with "Tricolor complex" which indicated that "Blitum complex" represents a loose assemblage of species. Close relationship between $A$. bengalense, A parganensis, A tricolor landrace, and popular $A$. tricolor varieties consolidates primarily the feasibility of their use as potential vegetable, though their nutritive values are to be evaluated.

Amaranths show wide range of sexuality from gynomonoecy, monoecy to dioecy. Monoecy is the predominant phenomenon in vegetable amaranths supposed to have originated from dominant bisexual condition (Mitchell and Diggle, 2005) in Cheno-Amaranth alliance through intermediate gynomonoecious or andromonoecious forms (Bawa and Beach, 1981). Dioecy is restricted in the subgen. Acnida. The close relationship between Chenopodiaceae and Amaranthaceae has been recognized based on core floral features (Hershkovitz, 1989). Molecular analysis of the Caryophyllales (Cuénoud et al., 2002) established the Chen-Am alliance as a monophyletic lineage. Gynomonoecious condition represents the intermediate stage between hermaphrodite and monoecious condition. Close association between "Tricolor complex" and gynomonoecious $A$. parganensis indicates that monoecious A. tricolor varieties might have originated from member like A. parganensis as recent introduction.

\section{CONCLUSION}

In the present investigation, few prominent findings were surfaced. There are few local morphotypes or landraces of A. tricolor and A. blitum beside the conventional popular cultivars, which are consumed locally. The close association between the popular cultivars with their local landraces have consolidated the feasibility of use of these landraces as potential vegetable, though their nutritive values are to be evaluated. Delimitation between "Tricolor complex" and "Blitum complex" is transient. Dehiscence or indehiscence of fruit cannot be a delimiting feature. The "Tricolor complex" represents a plexus of species, varieties, and landraces with varying degree of sexual behavior ranging from gynomonoecy to monoecy. Monoecious A. tricolor might have originated from a gynomonoecious member like $A$. parganensis as monoecy is considered as a derived stage from gynomonoecy.

\section{ACKNOWLEDGMENTS}

Author expresses his sincere gratitude to Dr. Duilio Iamonico of University of Rome Sapienza, Italy; Director of the Central National Herbarium, Howrah, Shibpur West Bengal, India for their necessary cooperation.

\section{REFERENCES}

Bawa KS, Beach JH. Evolution of sexual systems in flowering plants. Ann Mo Bot Gard 1981;68:254-74.

Brewbaker JL, Upadhya DM, Makinen Y, Macdonald T. Isozyme polymorphism in flowering plants, III. Gel electrophoretic methods and applications. Physiol Plant 1968;21:930-40.

Chan KF, Sun M. Genetic diversity and relationships detected by isozyme and RAPD analysis of crop and wild species of Amaranthus. Theor Appl Genet 1997;95:865-73.

Costea M, DeMason DA. Stem morphology and anatomy in Amaranthus L. (Amaranthaceae)-taxonomic significance. J Torrey Bot Soc 2001;128:254-81.

Costea M,Tardif FJ.The bracteoles in Amaranthus (Amaranthaceae): Their morphology, structure, function, and taxonomic significance. Sida 2003b;20:969-85.

Costea M, Brenner DM, Tardif FJ, TanYF, Sun M. Delimitation of Amaranthus cruentus L. and Amaranthus caudatus L. Using micromorphology and AFLP analysis: An application in germplasm identification. Genet Resour Crop Evol 2006;53:1625-33.

Cuénoud P, Savolainen V, Chatrou LW, Powell M, Grayer RJ, Chase MW. Molecular phylogenetics of Caryophyllales based on nuclear $18 \mathrm{~S}$ rDNA and plastid rbcL, atpB, and matK DNA sequences. Am J Bot 2002;89:132-44.

Das S.Taxonomical observation on the grain amaranths and new varieties of Amaranthus cruentus (Amaranthaceae). Nord J Bot 2012b;30:412-20.

Das S. Infraspecific variability of A. tricolor (Amaranthaceae) in India with a new variety. Phytotaxa 2013;88:25-30.

Das S, Iamonico D. Amaranthus bengalense (Amaranthaceae) a new species from India, with taxonomical notes on A. blitum aggregate. Phytotaxa 2014;181:293-300.

Das S. Amaranthus parganensis (Amaranthaceae), a new species from West Bengal, India. Novon 2015;23:406-10.

Hauptli H, Jain S. Allozyme variation and evolutionary relationships of grain amaranths (Amaranthus spp.). Theor Appl Genet 1984;69:153-65.

Hershkovitz MA. Phylogenetic studies in Centrospermae: 
A brief appraisal. Taxon 1989;38:602-8.

Iudina RS, Zheleznova NB, Zakharova OV, Zheleznov AV, Shumnyi VK. Isozyme analysis in a genetic collection of amaranths (Amaranthus L). Genetika 2005;41:1681-7.

Jayaprakasam B, Zhang Y, Nair MG. Tumor cell proliferation and cyclooxygenase enzyme inhibitory compounds in Amaranthus tricolor. J Agric Food Chem 2004;52:6939-43.

Mitchell CH, Diggle PK. The evolution of unisexual flowers: Morphological and functional convergence results from diverse developmental transitions. Am J Bot 2005;92:1068-76.

Mosyakin SL, Robertson KR. New infrageneric taxa and combination in Amaranthus (Amaranthaceae). Ann Bot Fenn 1996;33:275-81.

Nolan C, Noyes A, Bennett A, Hunter R, Hunter KL. Inter simple sequence repeats (ISSRs) reveal genetic variation among mid-Atlantic populations of threatened African Amaranthus pumilus and phylogenetic relationship. Castanea 2010;75:506-16.

Schnetzler KA, Breene WM. Food uses and amaranth product research: A comprehensive review. In: Peredes-Lopez O, editor. Amaranth Biology, Chemistry and Technology. Boca
Raton, FL: CRC Press; 1994. p. 155-84.

Stefunova V, Bezo M, Labajova M, Senkova S. Genetic analysis of three Amaranthus species using ISSR markers. Emir J Food Agric 2014;26:35-45.

Studier FW. Analysis of bacteriophage T7 early RNAs and proteins on slab gels. J Mol Biol 1973;79:237-48.

Transue DK, Fairabanks D, Robinson LR, Andersen WR. Species identification by RAPD analysis of grain amaranth genetic resources. Crop Sci 1994;34:1385-9.

WillettWC. Eat, Drink and be Healthy. New York: Free Press, A Division of Simon and Schuster Inc.; 2001. p. 132.

Wetter L, Dyck J. Isozyme analysis of cultured cells and somatic hybrids. In: Evans DA, SharpWR, Ammirato PV,YamadaY, editors. Handbook of Plant Cell Culture. New York: Macmillan Publishing Co.; 1983. p. 607-28.

Xu F, Sun M. Comparative analysis of phylogenetic relationships of grain amaranths and their wild relatives (Amaranthus: Amaranthaceae) using internal transcribed spacer, amplified fragment length polymorphism and doubleprimer fluorescent inter simple sequence repeat markers. Mol Phylogenet Evol 2001;21:372-87. 